\title{
Risk of pancreatic cancer in patients undergoing surgery for chronic pancreatitis
}

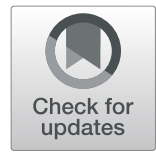

Zhenjiang Zheng, Yonghua Chen, Chunlu Tan, Nengwen Ke, Binqing Du and Xubao Liu*

\begin{abstract}
Background: Chronic pancreatitis (CP) is considered to be a risk factor for pancreatic cancer. A retrospective study was conducted to evaluate the incidence of pancreatic cancer after surgery for $\mathrm{CP}$ and to determine the risk factors.

Methods: The patients who underwent surgery for histologically documented CP between January 2009 and December 2017 were reviewed. The baseline characteristics, operative data, postoperative complications, and follow-up information were analysed. We calculated standardized incidence ratio on the base of the incidence of pancreatic cancer in the standard population in China. The risk factor for pancreatic cancer was assessed using Cox regression.

Results: Among 650 patients, pancreatic cancer was detected in 12 patients (1.8\%) after a median follow-up of 4.4 years. The standardized incidence ratio of pancreatic cancer was $68.12(95 \% \mathrm{Cl}, 35.20-118.99)$. Two independent risk factors for the development of pancreatic cancer in patients with chronic pancreatitis after surgery were identified: time interval to surgery [HR 1.005, 95\% Cl (1.002-1.008), $P=0.002$ ] and de novo endocrine insufficiency [HR 10.672, 95\% $\mathrm{Cl}(2.567-44.372), P=0.001]$.

Conclusions: Patients who require surgery for $\mathrm{CP}$ are at a very high risk of developing pancreatic cancer. Early surgical intervention plays a protective role in the development of pancreatic cancer from CP. A high index of suspicion for pancreatic cancer should be maintained in CP patients with de novo postoperative diabetes after surgery.
\end{abstract}

Keywords: Chronic pancreatitis, Pancreatic cancer, Surgery, Risk factor

\section{Background}

Chronic pancreatitis $(\mathrm{CP})$ is treated as one of risk factors affecting pancreatic cancer progression. The standardized incidence ratio (SIR) of pancreatic cancer in patients with CP was 11.8-20.22 with follow-up period after CP diagnosis of no less than two years [1-3]. As is well-known, it is usually difficult to make a differential diagnosis between pancreatic cancer and CP because these two kinds of diseases show similar radiological, biochemical as well as clinical features. [4]. On that account, there is a large possibility for pancreatic cancer being diagnosed as $\mathrm{CP}$. For eliminating patients who were diagnosed as $\mathrm{CP}$ but were likely to present pancreatic cancer, a large number of studies which evaluated the relation of $\mathrm{CP}$ to pancreatic cancer excluded those who saw the development of pancreatic cancer within $2-5$ years after being diagnosed as CP [5]. It is

\footnotetext{
* Correspondence: xbliu@medmail.com.cn

Department of Pancreatic Surgery, West China Hospital, Sichuan University, GuoXue Lane No.37, Chengdu 610041, Sichuan Province, China
}

undoubted that the exclusion strategy had the function of minimizing the risk of misclassification while it was arbitrary and subjective to determine the time nodes. To minimize misdiagnosis bias, this study focused on patients who underwent surgery for histopathological confirmed CP. In addition, surgical treatment of $\mathrm{CP}$ can provide good pain control and achieve a satisfactory quality of life in the majority of patients in long-term follow up [6]. However, there are limited data available regarding pancreatic cancer after surgery for $\mathrm{CP}$. We initiated a single-center cohort study to evaluate the incidence of pancreatic cancer after surgery for $\mathrm{CP}$ and to determine the risk factors.

\section{Methods \\ Patients}

Six hundred ninety two consecutive patients undergoing pancreatic operation between January 2009 and December 2017 for histologically confirmed CP were entered into a prospective database and retrospectively analysed. 
Two patients died of postoperative complications, 5 patients with autoimmune pancreatitis (AIP) and 1 patient underwent total pancreatectomy were excluded. 34 (4.9\%) patients were lost to follow-up. Clinical data of the remaining 650 patients included following parameters: demographics; clinical presentation; operative data; morbidity and follow-up information. Before operation, all patients underwent magnetic resonance cholangiopancreatography (MRCP), endoscopic retrograde cholangiopancreatography (ERCP), computed tomography, tumor markers or other examinations. Histological confirmation helped to establish the diagnosis of pancreatic cancer. The study has obtained the approval from the Ethics Committee of West China Hospital. The permission to access the data was obtained from the institutional review board of our hospital (fetch code: apqe5932!).

\section{Definitions}

Pancreatic fistula was defined as any measurable volume of drain fluid on or after postoperative day 3 with an amylase activity greater than 3 times the upper limit of normal serum amylase [7]. Biliary fistula was defined as bile drainage persisted for more than 5 days [8]. Exocrine insufficiency was defined as the presence of steatorrhea and/or the need for pancreatic enzyme replacement therapy. Endocrine pancreatic dysfunction was defined as the presence of diabetes. Time interval to surgery was defined as the time between initial diagnosis of $\mathrm{CP}$ and operative intervention.

\section{Surgical procedures}

Operations were performed by specialists in pancreatic surgery. All procedures were performed in open surgical technique. There was no minimal-invasive operation in the study group. The procedures treating $\mathrm{CP}$ are composed of pancreaticoduodenectomy (PD), distal pancreatectomy (DP), duodenum-preserving pancreatic head resection (DPPHR), [9] as well as lateral pancreatojejunostomy (Partington procedure). The pancreatic cancer diagnosis was excluded by virtue of the examination of intraoperative frozen section of resection specimen during the initial operation time together with postoperative pathological paraffin sections diagnosis or the immunohistochemical examination.

For the treatment of pancreatic cancer, surgical resection including PD, DP and residual total pancreatectomy was performed in patients with localized and clearly resectable disease. Unresectable tumor was treated with palliative care.

\section{Follow-up}

Patients or their relatives were followed up by outpatient visit or telephone contact every 6 months for the first 2 years and then yearly. Evaluations during the follow-up included questionnaires asking the pain status, the symptoms of diabetes or steatorrhea, and drug consumption. Furthermore, physical examinations, blood tests (e.g. CA19-9 levels) and abdominal CT scan were performed in the outpatient clinic of our hospital or a related hospital and clinic. The median follow-up was 4.4 years (ranging from 11 months to 10 years).

\section{Statistical analysis}

Standard statistical programs (SPSS for Windows, version 17.0; Chicago, Ill) was used to carry out all statistical analyses. Continuous data were expressed in the form of means and standard deviations and MannWhitney $U$ tests or Student's $t$-test was used to compared these data. Fisher exact test together with Chisquare test were carried out to compared categorical data. The cumulative incidence as well as the overall survival rate of pancreatic cancer after surgery of $\mathrm{CP}$ were estimated via the Kaplan-Meier method. The logrank test helped to test the difference. By definition, standardized incidence ratio (SIR) refers to the ratio of actual number of pancreatic cancers to estimated number in $\mathrm{CP}$ patient cohort, which could be used to indicate relative risk [1]. With regard to pancreatic cancer incidence in standard population of China, age stratification (based on an age interval of five years) on pancreatic cancer incidence in China in 2014 from the National Central Cancer Registry of China was used [10]. The univariate and multivariate Cox regression analyses were applied to assess the independent risk factors affecting the progression of pancreatic cancer after $\mathrm{CP}$ surgery [3]. All variables with univariable $P<0.1$ were considered for the multivariable model. The resulting hazard ratios (HR) with its $95 \%$ confidence intervals (CI) were presented. Two sided $P$ values were considered statistically significant at $P<0.05$.

\section{Results}

Incidence and survival for pancreatic cancer development after surgery of CP

In the last follow-up time, 12 cases $(1.8 \%)$ were diagnosed as pancreatic cancer based on the histology. The estimated number of pancreatic cancer patients reached 0.176, of which the SIR was 68.12 (95\%CI, 35.20-118.99). Pancreatic cancer exhibited cumulative incidence of $1.48 \%$ (95\% CI, $0.46-2.51 \%)$ at 3 years, $2.63 \%$ (95\% CI, $0.93-4.32 \%)$ at 6 years and $3.71 \%(95 \% \mathrm{CI}, 1.05-6.37 \%)$ at 9 years after CP surgery (Fig.1). Among the patients with pancreatic cancer, 8 patients underwent surgical resection involving PD in 6 , DP in 1 , and residual total pancreatectomy in 1 . Four patients had unresectable pancreatic cancer at the time of diagnosis. Thirty one patients were deceased at the end of follow-up. Cause of death was related to pancreatic cancer 
in 9 patients (1.4\%), other malignancies in 6 patients (1.1\%), causes related to $\mathrm{CP}$ in 1 patient $(0.2 \%)$, causes not related to $\mathrm{CP}$ in 7 (1.1\%), and unknown causes in $8(1.2 \%)$. Patients who had not developed to pancreatic cancer experienced better survival than those who had developed to pancreatic cancer [HR 17.071, 95\% CI (7.816-37.285), $P<0.001]$. The 1,3 and 5 years survival rate were 100 , 90.9 and $40.4 \%$, respectively in patients who had developed to pancreatic cancer, as opposed to 100, 98.7 and $94.6 \%$ in patients who had not developed to pancreatic cancer (Fig.2).

\section{Baseline characteristics}

According to development of cancer or not, the patients were divided into two groups, cancer group and noncancer group. The baseline characteristics of the two groups were showed in Table 1 . Patients in the cancer group had a longer time interval to surgery $(P=0.016)$. The other characteristics were comparable between the two groups.

\section{Operative data and postoperative complications}

Operating time, blood loss, blood transfusion, type of surgery, complications in terms of pancreatic fistula (grade $\mathrm{B}$ and $\mathrm{C}$ ), hemorrhage and bile fistula were showed in Table 2. Furthermore, complications according to the Clavien-Dindo classification (greater than grade $\geq 2$ ) [11], hospital stay after operation is recorded. There was no difference in the operative and postoperative data between the cancer and non-cancer group.

Pain, endocrine and exocrine functions at the last follow-up Pain status, endocrine and exocrine functions at the last follow-up were showed in Table 3. In all, 460 (70.8\%) patients reported no abdominal pain and 190 (29.2\%) of

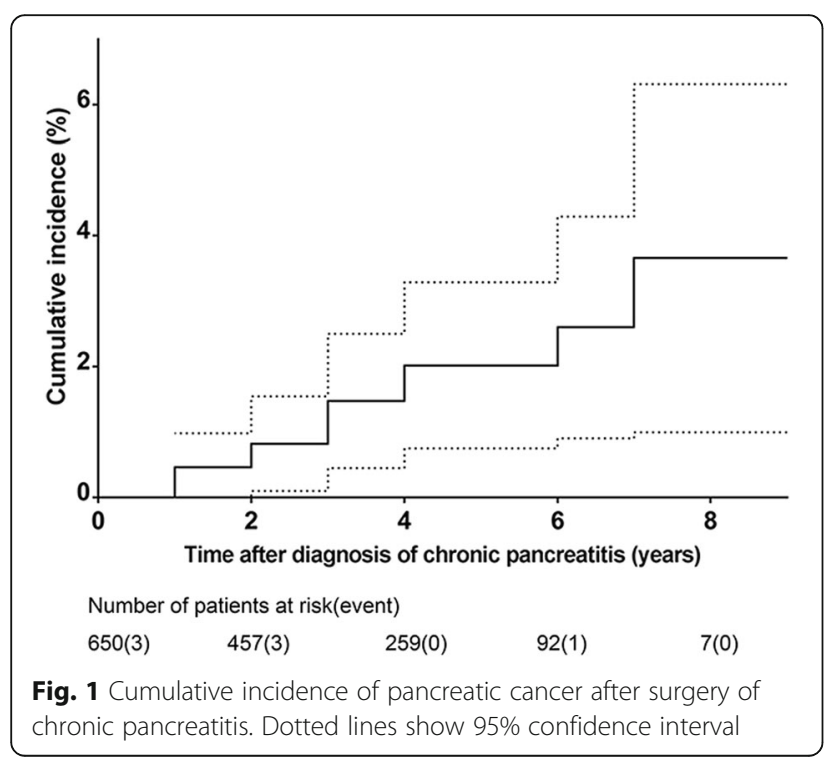

the patients had abdominal pain including 4 de novo pain $(0[0 \%]$ of 1 patients in the cancer group vs. 4 [7.4\%] of 54 patients in the non-cancer group, $P=1.0$ ) and 12 worsening pain (1 [9.1\%] of 11 patients in the cancer group vs. 11 [1.9\%] of 584 patients in the noncancer group, $P=0.202)$. A total of 274 patients $(42.2 \%)$ had endocrine insufficiency at the last follow-up evaluation. The incidence of total postoperative endocrine insufficiency was not significantly different between the two groups. 26 of the 402 patients without preoperative diabetes had de novo endocrine insufficiency. The incidence of de novo endocrine insufficiency was higher in the cancer group, occurring in $4(50.0 \%)$ of 8 patients in the cancer group and $22(5.6 \%)$ of 394 patients in the non-cancer group $(P=0.001)$. In the last follow-up time, 35 cases exhibited exocrine insufficiency, thus 154 cases (23.7\%) exhibited exocrine pancreatic insufficiency in total. The two groups showed no significant difference in term of the de novo or total postoperative exocrine insufficiency incidence.

\section{Risk factors affecting progression of pancreatic cancer following $\mathrm{CP}$ surgery}

Twelve CP patients showed pancreatic cancer after surgery. The influences of baseline characteristics, perioperative data, postoperative pain, postoperative endocrine and exocrine functions, and abstinence from tobacco or alcohol after surgery were summarized in Table 4. Time interval to surgery, worsening pain, total postoperative endocrine insufficiency and de novo endocrine insufficiency were associated with high risk of pancreatic cancer in univariate analysis. Factors that affected pancreatic cancer development at the $P<0.10$ level of significance by univariate analysis were included in a multivariate Cox regression model. After adjusting for these variables, time interval to surgery [HR 1.005, 95\% CI (1.002-1.008), $P=0.002]$ and de novo endocrine insufficiency $[\mathrm{HR}$ 10.672, 95\% CI (2.567-44.372), $P=$ 0.001] were found to be independent variable influencing pancreatic cancer development.

\section{Discussion}

$\mathrm{CP}$ has been reported as one of risk factors affecting pancreatic cancer progression. Based on study by Löwenfels et al. [2], pancreatic cancer exhibited a SIR of 16.5 in a terrain of CP over 2 years of follow-up, and a SIR of 14.4 over 5 years of follow-up. As published by Hao et al. [3], pancreatic cancer in $1656 \mathrm{CP}$ patients showed a SIR of 20.22 in China. According to a recent metaanalysis, 5 years after being diagnosed as chronic pancreatitis, the risk of pancreatic cancer increased by nearly eight fold [5]. In the study, we observed pancreatic cancer in 12 patients $(1.8 \%)$ with histologically confirmed CP following surgery ina median follow-up of 


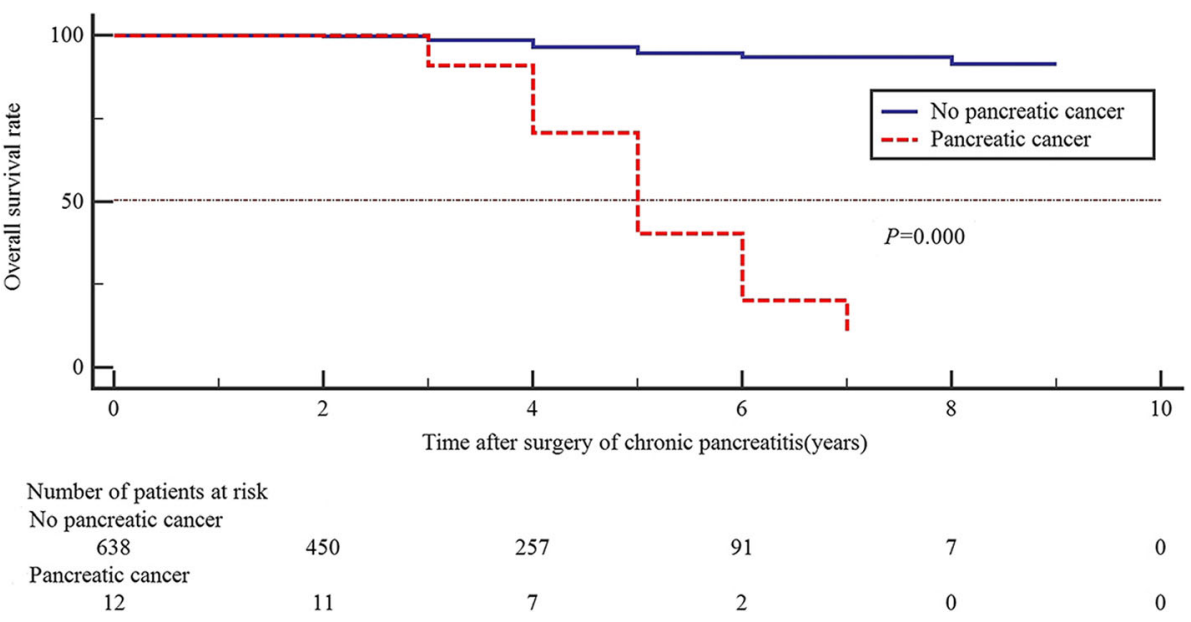

Fig. 2 Comparison of overall survival rate between patients who had not developed to pancreatic cancer to those who had developed to pancreatic cancer

4.4 years. The expected number of pancreatic cancer was 0.176 , of which the SIR was 68.12. Pancreatic cancer exhibited a cumulative incidence of 3.71\% (95\% CI, 1.05$6.37 \%)$ at the end of follow-up. There are 2 risk factors regarding the pancreatic cancer,1) time interval to surgery; 2) de novo endocrine insufficiency.

$\mathrm{CP}$ is a kind of disease with extensive parenchymal fibrosis of pancreas and can be divided into obstructive form, calcifying form as well as steroid-responsive form [12]. As is well known, the inflammatory process may cause cancer, making people believe that pancreatic cancer can be caused by chronic inflammation of pancreatic parenchyma. The relationship shows similarity to that between esophageal cancer and Barrett's epithelium, between hepatic cancer and cirrhosis, between cholangiocarcinoma and sclerosing cholangitis, and between colon cancer and ulcerative colitis [13]. Nevertheless, we are still unknown about the mechanism of the relationship between CP and pancreatic cancer. Based on reports, pancreatic acinar contains a sufficient activity level of Ras, which proves that CP is directly linked with pancreatic cancer [14]. In addition, both pancreatic

Table 1 Baseline characteristics of the patients

\begin{tabular}{|c|c|c|c|}
\hline Characteristics & Cancer group (\%) $(n=12)$ & Non-cancer group (\%) $(n=638)$ & $P$ \\
\hline Sex, (Male: Female) & $9: 3$ & $501: 137$ & 0.728 \\
\hline Age, (yrs) & $48.3 \pm 7.2$ & $45.4 \pm 13.5$ & 0.587 \\
\hline Time interval to surgery, (mons) & $96.6 \pm 164.4$ & $36.4 \pm 74.2$ & 0.016 \\
\hline Etiology & & & 0.751 \\
\hline Alcoholic & $7(58.3)$ & $354(55.5)$ & - \\
\hline Idiopathic & $5(41.7)$ & $222(34.8)$ & - \\
\hline Hereditary & $0(0)$ & $62(9.7)$ & - \\
\hline Smoking & & & 0.180 \\
\hline past & $1(8.3)$ & $104(16.3)$ & - \\
\hline current & $9(75.0)$ & $298(46.7)$ & - \\
\hline never & $2(16.7)$ & $236(37.0)$ & - \\
\hline Alcohol consumption & & & 1.0 \\
\hline past & $1(8.3)$ & $55(8.6)$ & - \\
\hline current & $9(75.0)$ & $441(69.1)$ & - \\
\hline never & $2(16.7)$ & $142(22.3)$ & - \\
\hline Pain & $11(91.7 \%)$ & $584(91.5 \%)$ & 0.987 \\
\hline Steatorrhea & $2(16.7 \%)$ & $117(18.3 \%)$ & 0.882 \\
\hline Diabetes & $4(33.3 \%)$ & $244(38.2 \%)$ & 0.729 \\
\hline
\end{tabular}


Table $\mathbf{2}$ Operative data and postoperative complications

\begin{tabular}{|c|c|c|c|}
\hline Characteristics & Cancer group (\%) $(n=12)$ & Non-cancer group (\%) $(n=638)$ & $P$ \\
\hline Operating time, (min) & $200.8 \pm 37.3$ & $209.1 \pm 47.3$ & 0.643 \\
\hline Blood loss, (ml) & $225.0 \pm 121.5$ & $219.1 \pm 248.0$ & 0.168 \\
\hline Blood transfusion & $1(8.3 \%)$ & $33(5.2 \%)$ & 0.478 \\
\hline Type of surgery & & & 0.190 \\
\hline PD & $0(0)$ & $59(9.2)$ & - \\
\hline DPPHR & $10(83.3)$ & $325(50.9)$ & - \\
\hline DP & $1(8.3)$ & $66(10.3)$ & - \\
\hline Partington procedure & $1(8.3)$ & $188(29.5)$ & - \\
\hline Pancreatic fistula & $0(0)$ & $14(2.2)$ & 1.0 \\
\hline Hemorrhage & $0(0)$ & $10(1.6)$ & 1.0 \\
\hline Biliary fistula & $0(0)$ & $1(0.2)$ & 1.0 \\
\hline Complications (greater than grade $\geq 2$ ) & $1(8.3)$ & $11(1.7)$ & 0.202 \\
\hline Hospital stay after operation, (days) & $7.9 \pm 2.0$ & $9.4 \pm 6.9$ & 0.571 \\
\hline
\end{tabular}

PD, pancreaticoduodenectomy; DPPHR, duodenum-preserving pancreatic head resection; DP, distal pancreatectomy

cancer tissue and $\mathrm{CP}$ have same dysregulated signaling pathways, such as nuclear factor kappa B, cytokines, peroxisome proliferator-activated receptor- $\gamma$, as well as reactive oxygen species [15]. However, there is possibly no identical genetic susceptibility between pancreatic cancer and $\mathrm{CP}$, at least in the variants with high frequency [16].

The surgical intervention indications of $\mathrm{CP}$ were composed of intractable pain, malignancy suspicion, as well as local complications [9]. CP patients who had not underwent surgery exhibited a much higher possibility in developing pancreatic cancer compared with those who received surgery [1]. This kind of diversity might be because the fibrotic pancreatic parenchyma was resected and pancreatic inflammation was relieved through surgical drainage. However, the SIR of pancreatic cancer in patients with $\mathrm{CP}$ after surgery found in our study was higher compared with other studies in which not all patients with $\mathrm{CP}$ underwent surgery [1-3]. This is may be because the age-specific incidence of pancreatic cancer is various in different countries and regions, result in the expected number of cancer cases was different. Thus, further studies evaluating the incidence of pancreatic cancer among patients with $\mathrm{CP}$ underwent surgery compared with no surgery are required. As reported by Lamme et al., early surgical drainage of chronic obstructive pancreatitis improved recovery of histology grades and pancreatic exocrine function compared to late surgical drainage in animal model [17]. A system review demonstrated that early surgery was benefit for postoperative pain relief, preservation pancreatic function and the need for further intervention in patient with CP [18]. Our study showed the time interval to surgery for $\mathrm{CP}$ is independent risk factor influencing pancreatic cancer development. Early surgical intervention plays a protective role in the development of pancreatic cancer from CP. In our study, the other independent risk factor of developing pancreatic cancer was de novo postoperative endocrine insufficiency. It was demonstrated that newly diagnosed diabetes was strong association with pancreatic cancer [19]. Therefore, it is possible that the presence of de novo postoperative endocrine insufficiency may be not only attribute to further ongoing parenchyma destruction by $\mathrm{CP}$, but also as predictor of pancreatic cancer. It was analogous to considering periportal lymphadenopathy as a pioneer of various diseases [20].

Table 3 Pain, exocrine and endocrine functions at the last follow-up

\begin{tabular}{llll}
\hline Characteristics & Cancer group $(\mathrm{n}=12)$ & Non-cancer group $(\mathrm{n}=638)$ & $P$ \\
\hline Postoperative abdominal pain & $6(50 \%)$ & $184(28.8 \%)$ & $4(7.4 \%)$ of 54 patients \\
De novo pain & $0(0 \%)$ of 1 patient & $11(1.9 \%)$ of 584 patients & 0.110 \\
Worsening pain & $1(9.1 \%)$ of 11 patients & $266(41.7 \%)$ & 0.202 \\
Total postoperative endocrine insufficiency & $8(66.7 \%)$ & $22(5.6 \%)$ of 394 patients & 0.083 \\
De novo endocrine insufficiency & $4(50.0 \%)$ of 8 patients & $151(23.7 \%)$ & 0.001 \\
Total postoperative exocrine insufficiency & $3(25 \%)$ & $34(6.5 \%)$ of 521 patients & 0.914 \\
De novo exocrine insufficiency & $1(10.0 \%)$ of 10 patients & & 0.497 \\
\hline
\end{tabular}


Table 4 Results of univariable and multivariable regression for pancreatic cancer after surgery of CP

\begin{tabular}{|c|c|c|c|c|}
\hline \multirow[t]{2}{*}{ Variables } & \multicolumn{2}{|l|}{ Univariate analysis } & \multicolumn{2}{|l|}{ Multivariate analysis } \\
\hline & $\mathrm{HR}(95 \% \mathrm{Cl})$ & $P$ & $\mathrm{HR}(95 \% \mathrm{Cl})$ & $P$ \\
\hline \multicolumn{5}{|l|}{ Sex } \\
\hline Male & $0.811(0.219-2.997)$ & 0.753 & & \\
\hline Female & 1.0 & & & \\
\hline \multicolumn{5}{|l|}{ Age, (yrs) } \\
\hline$\leq 50$ & 1 & 0.386 & & \\
\hline$>50$ & $0.561(0.152-2.072)$ & & & \\
\hline Time interval to surgery, (mons) & $1.005(1.002-1.008)$ & 0.002 & $1.005(1.002-1.008)$ & 0.002 \\
\hline Etiology & & 0.995 & & \\
\hline Alcoholic & $0.942(0.299-2.971)$ & 0.919 & & \\
\hline Idiopathic & 1 & & & \\
\hline Hereditary & 0.000 & 0.985 & & \\
\hline Smoking & & 0.222 & & \\
\hline past & $1.215(0.110-13.401)$ & 0.874 & & \\
\hline current & $3.378(0.730-15.642)$ & 0.119 & & \\
\hline never & 1 & & & \\
\hline Alcohol consumption & & 0.719 & & \\
\hline past & $2.761(0.238-32.048)$ & 0.417 & & \\
\hline current & 1.383(0.299-6.402) & 0.678 & & \\
\hline never & 1 & & & \\
\hline \multicolumn{5}{|l|}{ Preoperative pain } \\
\hline Yes & $1.081(0.139-8.381)$ & 0.941 & & \\
\hline No & 1 & & & \\
\hline \multicolumn{5}{|l|}{ Preoperative steatorrhea } \\
\hline Yes & $1.044(0.228-4.782)$ & 0.958 & & \\
\hline No & 1 & & & \\
\hline \multicolumn{5}{|l|}{ Preoperative diabetes } \\
\hline Yes & $0.851(0.255-2.840)$ & 0.793 & & \\
\hline No & 1 & & & \\
\hline \multicolumn{5}{|l|}{ Operating time, $\min$} \\
\hline$\leq 180$ & 1 & 0.803 & & \\
\hline$>180$ & $1.165(0.351-3.874)$ & & & \\
\hline \multicolumn{5}{|l|}{ Blood loss, ml } \\
\hline$\leq 200$ & 1 & 0.390 & & \\
\hline$>200$ & $1.694(0.509-5.641)$ & & & \\
\hline \multicolumn{5}{|l|}{ Blood transfusion } \\
\hline Yes & $1.864(0.240-14.471)$ & 0.552 & & \\
\hline No & 1 & & & \\
\hline \multicolumn{5}{|l|}{ Type of surgery } \\
\hline PD & 0.000 & 0.986 & & \\
\hline DPPHR & $6.671(0.852-52.242)$ & 0.71 & & \\
\hline DP & $2.857(0.179-45.694)$ & 0.458 & & \\
\hline Partington procedure & 1 & & & \\
\hline Pancreatic fistula & & & & \\
\hline
\end{tabular}


Table 4 Results of univariable and multivariable regression for pancreatic cancer after surgery of CP (Continued)

\begin{tabular}{|c|c|c|c|c|}
\hline \multirow[t]{2}{*}{ Variables } & \multicolumn{2}{|l|}{ Univariate analysis } & \multicolumn{2}{|l|}{ Multivariate analysis } \\
\hline & $\mathrm{HR}(95 \% \mathrm{Cl})$ & $P$ & $\mathrm{HR}(95 \% \mathrm{Cl})$ & $P$ \\
\hline Yes & $0.48(0.000-7,203,834.567)$ & 0.752 & & \\
\hline No & 1 & & & \\
\hline \multicolumn{5}{|l|}{ Hemorrhage } \\
\hline Yes & $0.049(0.000-71,526,595.29)$ & 0.779 & & \\
\hline No & 1 & & & \\
\hline \multicolumn{5}{|l|}{ Biliary fistula } \\
\hline Yes & $0.50(0.000-2.309 \mathrm{E}+26)$ & 0.926 & & \\
\hline No & 1 & & & \\
\hline \multicolumn{5}{|l|}{ Complications (greater than grade $\geq 2$ ) } \\
\hline Yes & $5.338(0.687-41.512)$ & 0.109 & & \\
\hline No & 1 & & & \\
\hline \multicolumn{5}{|l|}{ Hospital stay after operation, (days) } \\
\hline$\leq 7$ & 1 & & & \\
\hline$>7$ & $0.803(0.252-2.556)$ & 0.710 & & \\
\hline \multicolumn{5}{|l|}{ Postoperative abdominal pain } \\
\hline Yes & $2.457(0.792-7.619)$ & 0.120 & & \\
\hline No & 1 & & & \\
\hline \multicolumn{5}{|l|}{ De novo pain } \\
\hline Yes & $0.49(0.000-6.085 E+10)$ & 0.832 & & \\
\hline No & 1 & & & \\
\hline Worsening pain & & & & 0.358 \\
\hline Yes & $5.606(0.721-43.560)$ & 0.099 & & \\
\hline No & 1 & & & \\
\hline Total postoperative endocrine insufficiency & & & & 0.579 \\
\hline Yes & $2.949(0.883-9.851)$ & 0.079 & & \\
\hline No & 1 & & & \\
\hline De novo endocrine insufficiency & & & $10.672(2.567-44.372)$ & 0.001 \\
\hline Yes & $13.106(3.944-43.552)$ & 0.000 & & \\
\hline No & 1 & & & \\
\hline \multicolumn{5}{|l|}{ Total postoperative exocrine insufficiency } \\
\hline Yes & $1.121(0.303-4.144)$ & 0.864 & & \\
\hline No & 1 & & & \\
\hline \multicolumn{5}{|l|}{ De novo exocrine insufficiency } \\
\hline Yes & $1.242(0.159-9.681)$ & 0.836 & & \\
\hline No & 1 & & & \\
\hline \multicolumn{5}{|l|}{ Give up smoking } \\
\hline Yes & $2.623(0.790-8.714)$ & 0.115 & & \\
\hline No & 1 & & & \\
\hline \multicolumn{5}{|l|}{ Give up drinking } \\
\hline Yes & $2.009(0.637-6.340)$ & 0.234 & & \\
\hline No & 1 & & & \\
\hline
\end{tabular}

HR Hazard ratio, Cl Confidence interval, $P D$ pancreaticoduodenectomy, DPPHR, duodenum-preserving pancreatic head resection, DP, distal pancreatectomy 
In earlier studies [21, 22], alcohol consumption and smoking were considered as risk factors for the development of pancreatic cancer from CP. However, based on a pooled analysis on 12 cohort researches, there is no association between total alcohol intake and risk of pancreatic cancer [23]. According to study by Hao et al. [3], for people who smoke for over 60 packs each year, the risk of getting pancreatic cancer increased by 12 folds, while smoking without taking into account dose showed no significant difference. Kirkegård et al. [5] performed a meta-analysis and systematic review, finding the difficulty in assessing how alcohol and smoking affected $\mathrm{CP}$ developing into pancreatic cancer.. As demonstrated by Anderson et al. [21], the negative impact of alcohol and tobacco on pancreas will last for ten years. Our study demonstrated that abstinence from tobacco or alcohol after surgery of $\mathrm{CP}$ could not decrease risk factor for pancreatic cancer.

Despite of the application of advanced diagnostic approaches in recent years, it remains difficult to distinguish pancreatic cancer from CP. Based on existing study, nearly $5 \%$ of pancreatic cancers were misdiagnosed as CP in initial stage, the diagnosis of two-thirds of whom was delayed by two months to two years [24]. As we know, based on a majority of studies which evaluated the association of $\mathrm{CP}$ with pancreatic cancer, $\mathrm{CP}$ diagnosis was not determined according to the microscopic examination of the surgical specimens. Two studies assessed self-reported pancreatitis [25, 26], 4 studies evaluated patients via the International Classification of Diseases codes [27-30], and 1 study assessed patients from 1946 [2], in which period the risk of misdiagnosis was increased due to outdated diagnosis tools. Therefore, exclusion of patients who had been diagnosed within no less than two years after CP diagnosis would minimize the misdiagnosis bias [1]. The selection of lag period seems not to be evidence based and more likely arbitrary. Pathological examination is the gold standard for the diagnosis of diseases [31]. In our study, the diagnosis of $\mathrm{CP}$ was confirmed by histopathologic study of resection specimen, in order to eliminate misdiagnosis bias.

There are some limitations in our study. Firstly, this is a retrospective study that precision and completeness of data acquisition are difficult to control. Secondly, the data with regard to daily dose of smoking and alcohol consumption was lacking. Thus, whether smoking and alcohol consumption are dose-related to development of pancreatic cancer after surgery of $\mathrm{CP}$ has not been analysed. Thirdly, the limited size of pancreatic cancer patients may reduce statistical power.

\section{Conclusions}

To sum up, according to the study, patients who require surgery for $\mathrm{CP}$ are more likely to develop pancreatic cancer. Time interval to surgery and de novo endocrine insufficiency were the risk factors affecting the pancreatic cancer progression in $\mathrm{CP}$ patients following surgery. The surgical intervention in early stage greatly affects $\mathrm{CP}$ developing into pancreatic cancer. It is necessary to maintain a high suspicion index for pancreatic cancer in $\mathrm{CP}$ patients showing de novo postoperative diabetes following the surgery.

\section{Abbreviations}

Cl: Confidence intervals; CP: Chronic pancreatitis; DP: Distal pancreatectomy; HR: Hazard ratios; PD: Pancreaticoduodenectomy; SIR: Standardized incidence ratio

Acknowledgements

We thank Dr. Ming Li for data collection of this study.

Authors' contributions

All the authors participated in surgical treatment for the patients in this study. ZZ analyzed and interpreted the patient data and was a major contributor in writing the manuscript. YC and CT reviewed and edited the manuscript. NK and BD collected the patients' data. XL was responsible for the study conception, design, data analysis and drafting of the manuscript. All authors read and approved the final manuscript.

Funding

This work was supported by the 1.3.5 project for disciplines of excellenceClinical Research Incubation Project, West China Hospital, Sichuan University; National Natural Science Foundation of China (81602133); Scientific and Technological Support Program of Sichuan Province (2016FZ0115).

Availability of data and materials

The datasets generated and/or analysed during the current study are available from the corresponding author on reasonable request.

Ethics approval and consent to participate

This study was reviewed and approved by the institutional Ethical Board of West China Hospital of Sichuan University. And the need for informed consent was waived due to the retrospective nature of the study.

Consent for publication

Not applicable.

\section{Competing interests}

The authors declare that they have no competing interests.

Received: 9 April 2019 Accepted: 20 June 2019

Published online: 08 July 2019

References

1. Ueda J, Tanaka M, Ohtsuka T, et al. Surgery for chronic pancreatitis decreases the risk for pancreatic cancer: a multicenter retrospective analysis. Surgery. 2013;153(3):357-64.

2. Lowenfels $A B$, Maisonneuve $P$, Cavallini $G$, et al. Pancreatitis and the risk of pancreatic cancer. International Pancreatitis Study Group N Engl J Med. 1993:328(20):1433-7.

3. Hao $L$, Zeng XP, Xin $L$, et al. Incidence of and risk factors for pancreatic cancer in chronic pancreatitis: a cohort of 1656 patients. Dig Liver Dis. 2017; 49(11):1249-56.

4. Klöppel G, Adsay NV. Chronic pancreatitis and the differential diagnosis versus pancreatic cancer. Arch Pathol Lab Med. 2009;133(3):382-7.

5. Kirkegård J, Mortensen FV, Cronin-Fenton D. Chronic pancreatitis and pancreatic Cancer risk: a systematic review and meta-analysis. Am J Gastroenterol. 2017;112(9):1366-72.

6. Schnelldorfer T, Lewin DN, Adams DB. Operative management of chronic pancreatitis: longterm results in 372 patients. J Am Coll Surg. 2007;204(5): 1039-45 discussion 1045-7.

7. Bassi C, Marchegiani G, Dervenis C, et al. The 2016 update of the international study group (ISGPS) definition and grading of postoperative pancreatic fistula: 11 years after. Surgery. 2017;161(3):584-91. 
8. Murakami Y, Uemura K, Hayashidani Y, et al. No mortality after 150 consecutive pancreatoduodenctomies with duct-to-mucosa pancreaticogastrostomy. J Surg Oncol. 2008;97(3):205-9.

9. Zheng Z, Xiang G, Tan C, et al. Pancreaticoduodenectomy versus duodenum-preserving pancreatic head resection for the treatment of chronic pancreatitis. Pancreas. 2012;41(1):147-52.

10. Chen W, Sun K, Zheng R, et al. Cancer incidence and mortality in China 2014. Chin J Cancer Res. 2018;30(1):1-12.

11. Dindo D, Demartines N, Clavien PA. Classification of surgical complications: a new proposal with evaluation in a cohort of 6336 patients and results of a survey. Ann Surg. 2004;240(2):205-13.

12. Majumder S, Chari ST. Chronic pancreatitis. Lancet. 2016;387(10031):1957-66.

13. Sakorafas GH, Sarr MG. Pancreatic cancer after surgery for chronic pancreatitis. Dig Liver Dis. 2003;35(7):482-5.

14. Ji B, Tsou L, Wang $H$, et al. Ras activity levels control the development of pancreatic diseases. Gastroenterology. 2009;137(3):1072-82, 1082.e1-6.

15. Kong $X$, Sun $T$, Kong F, et al. Chronic pancreatitis and pancreatic Cancer. Gastrointest Tumors. 2014;1(3):123-34

16. Campa D, Pastore M, Capurso G, et al. Do pancreatic cancer and chronic pancreatitis share the same genetic risk factors? A PANcreatic disease ReseArch (PANDoRA) consortium investigation. Int J Cancer. 2018;142(2): 290-6.

17. Lamme B, Boermeester MA, Straatsburg $\mathbb{H}$, et al. Early versus late surgical drainage for obstructive pancreatitis in an experimental model. $\mathrm{Br}$ J Surg. 2007;94(7):849-54.

18. Yang CJ, Bliss LA, Schapira EF, et al. Systematic review of early surgery for chronic pancreatitis: impact on pain, pancreatic function, and reintervention. J Gastrointest Surg. 2014;18(10):1863-9.

19. Dankner R, Boffetta $P$, Balicer RD, et al. Time-dependent risk of Cancer after a diabetes diagnosis in a cohort of 2.3 million adults. Am J Epidemiol. 2016; 183(12):1098-106.

20. Arda Işık, Deniz Firat, Mehmet Soyturk, et al. Idiopathic periportal lymphadenopathy. GMJ. 2016; 27(2): 51-52.

21. Anderson MA, Zolotarevsky E, Cooper KL, et al. Alcohol and tobacco lower the age of presentation in sporadic pancreatic cancer in a dose-dependent manner: a multicenter study. Am J Gastroenterol. 2012;107(11):1730-9.

22. Brand RE, Greer JB, Zolotarevsky E, et al. Pancreatic cancer patients who smoke and drink are diagnosed at younger ages. Clin Gastroenterol Hepatol. 2009;7(9):1007-12.

23. Michaud DS, Vrieling A, Jiao L, et al. Alcohol intake and pancreatic cancer: a pooled analysis from the pancreatic cancer cohort consortium (PanScan). Cancer Causes Control. 2010;21(8):1213-25.

24. Munigala S, Kanwal F, Xian H, et al. New diagnosis of chronic pancreatitis: risk of missing an underlying pancreatic cancer. Am J Gastroenterol. 2014; 109(11):1824-30

25. Anderson LN, Cotterchio M, Gallinger S. Lifestyle, dietary, and medical history factors associated with pancreatic cancer risk in Ontario, Canada. Cancer Causes Control. 2009;20(6):825-34

26. Duell EJ, Casella DP, Burk RD, et al. Inflammation, genetic polymorphisms in proinflammatory genes TNF-A, RANTES, and CCR5, and risk of pancreatic adenocarcinoma. Cancer Epidemiol Biomark Prev. 2006;15(4):726-31.

27. Bang UC, Benfield T, Hyldstrup L, et al. Mortality, cancer, and comorbidities associated with chronic pancreatitis: a Danish nationwide matched-cohort study. Gastroenterology. 2014;146(4):989-94.

28. Bansal P, Sonnenberg A. Pancreatitis is a risk factor for pancreatic cancer. Gastroenterology. 1995;109(1):247-51.

29. Goldacre MJ, Wotton CJ, Yeates D, et al. Liver cirrhosis, other liver diseases, pancreatitis and subsequent cancer: record linkage study. Eur J Gastroenterol Hepatol. 2008:20(5):384-92.

30. Karlson BM, Ekbom A, Josefsson S, et al. The risk of pancreatic cancer following pancreatitis: an association due to confounding? Gastroenterology. 1997;113(2):587-92.

31. Ișık A, Sayar I, Gülhan B, Fırat D. Fascioliasis: a rare case mimicking cholelithiasis. South Clin Ist Euras. 2016;27(2):145-6.

\section{Publisher's Note}

Springer Nature remains neutral with regard to jurisdictional claims in published maps and institutional affiliations.

\section{Ready to submit your research? Choose BMC and benefit from:}

- fast, convenient online submission

- thorough peer review by experienced researchers in your field

- rapid publication on acceptance

- support for research data, including large and complex data types

- gold Open Access which fosters wider collaboration and increased citations

- maximum visibility for your research: over $100 \mathrm{M}$ website views per year

At $\mathrm{BMC}$, research is always in progress.

Learn more biomedcentral.com/submissions 